abordaron los trabajos definitivos de la pintura hacia $1662-1663^{12}$, estos recuerdos portugueses, que ya campeaban en el retablo mayor de la iglesia ${ }^{13}$, fueron suprimidos.

Los primeros tanteos para la decoración de San Antonio estaban ya en marcha en 1660 y es problable que la vuelta de Colonna a Italia en 1662 supusiera una detención en el ritmo de los trabajos que luego retomarían Rizi y Carreño, quienes habían colaborado con el italiano en el Alcázar Real y en el Buen Retiro. Ambos pintores recibieron pagos en 1663, pero la obra debió ir lenta, hasta que en 1666 la falta de medios económicos obligó a la Hermandad a suspender la obra cuando la cúpula ya estaba terminada, desistiendo en su idea inicial de pintar también los muros de la iglesia ${ }^{14}$. En distintas fechas los pintores habían ido recibiendo cantidades de 3.000 reales: el 21 de septiembre y el 11 de noviembre de 1663 ; el 21 de enero de 1664; el 25 de agosto y el 4 de octubre de 1665 y el 21 de febrero de 1666, por todas cuyas cantidades dieron carta de pago el 12 de diciembre de $1665^{15}$, que se sumaban a los 31.558 reales recibidos en $1663^{16}$. Aunque las sumas no cuadran completamente, consta por resúmenes de cuentas de la Hermandad que el gasto de toda la pintura ascendió, con la cúpula acabada, a 61.730 reales ${ }^{17}$.

ISMAEL GUTIÉRREZ PASTOR Universidad Autónoma de Madrid

\title{
ENTRE LA VIDA Y LA MUERTE. $=6$ NUEVAS APORTACIONES DOCUMENTALES SOBRE VELÁZQUEZ EN SEVILLA
}

Los documentos descubiertos en los dos últimos años sobre Velázquez por diferentes investigadores están ayudando a conocer mejor la vida y obra del pintor, todavía repleta de sombras en cuanto a su personalidad. Este artículo recoge las últimas contribuciones docu-

12 Sobre la cronología de las pinturas de Rizi y Carreño en San Antonio de los Portugueses, las dudas y fechas relativas expuestas por Tormo y por Angulo Iñiguez, así por quienes han seguido sus textos, han sido parcialmente renovadas por el Conde de Tepa, Breve historia de la Santa, Pontificia Hermandad del Refugio y Piedad de Madrid. Madrid, 1995, pp. 35-36, donde transcribe parcialmente algunos acuerdos de la Hermandad de San Antonio. Y con mayor precisión por Gutiérrez Pastor-Arranz Otero, op. cit., 1999 (en prensa).

${ }_{13}$ El retablo mayor con los lienzos de Vicente Carducho y la imagen de San Antonio de Padua de Manuel Pereira había sido contratado por Juan Bautista Garrido en 1630, pero en 1631 se agrandó, extendiéndolo fuera del arco del presbiterio por las paredes laterales, siendo obra de Miguel Tomás. Llegaba hasta la"cornisa del templo y en las enjutas entre la estructura y el arco había dos escudos de Portugal ( $C f r$. Gutiérrez Pastor-Arranz Otero, op. cit., 1999 (en prensa).

${ }_{14}$ En 1660 la Hermandad de San Antonio ya tenía intención de pintar totalmente el interior de la iglesia. En 1661 las obras parece que llevaron buen ritmo, pero hasta el 31 de julio de 1663 no consta el pago a Rizi y a Carreño de 31.558 reales. El 22 de marzo de 1665 se esperaba poder «acabar de pintar la iglesia» (no la cúpula) y el 18 de julio de 1666 la Hermandad acordó que no se prosiguiera la pintura «de cornisa para abajo, en la conformidad que está hecha de pintura (sic) para arriba» dada la falta de medios (Archivo de la Santa Real Pontificia Hermandad del Refugio. San Antonio. Legajo 517, libro 2 (1656) de Actas de la cofradía de San Antonio, fols. 14-14 v. ${ }^{\circ}, 19,20-20$ v. $^{\circ}$ y sin foliar las siguientes referencias. Cfr. Gutiérrez Pastor-Arranz Otero, op. cit., 1999 (en prensa).

is Archivo Histórico de Protocolos. Madrid. Protocolo 8973, fols. 781-781 v.‥

16 Archivo Histórico de Protocolos. Madrid. Protocolo 8973, fols. 370-370 v. .

17 Archivo Histórico Nacional. Madrid. Consejos, legajo 17.221. 
mentales sobre la primera etapa de Diego Velázquez, aquella que transcurre en su ciudad natal, aportando la transcripción de los documentos descubiertos y analizados en el Catálogo de la Exposición «Velázquez y Sevilla» ${ }^{1}$, ya que hasta el momento no habían sido publicados en un corpus documental, junto con los testamentos inéditos de los padres del pintor sevillano, que constituyen una novedad de gran importancia para conocer el ambiente en el que vivió el joven artista. El apéndice documental que se acompaña podrá, junto con otros documentos ya publicados, mejorar el conocimiento de la primera etapa velazqueña, sujeta todavía a nuevas lecturas.

El contenido de esta documentación muestra algunas particularidades de la vida que rodeaba al Velázquez sevillano. De su biografía juvenil era muy parco lo que se conocía, sólo por algunos documentos se tenían constancia de su aprendizaje con Pacheco, su carta de examen, su matrimonio, sus hijas y la noticia de un único aprendiz, Diego Melgar. Sin embargo, esto era insuficiente para realizar cualquier análisis sobre su familia y sus primeras relaciones en la ciudad, apenas reseñadas por los testimonios de Pacheco y Palomino. En este sentido, el estudio del artista no podía ser completo sin conocer sus orígenes. Gracias al descubrimiento de una serie de documentos sobre su familia hemos podido aclarar ciertos misterios sobre el origen del pintor. Estas informaciones han permitido conocer la familia del artista, descubriendo cuales eran los oficios de su abuelo, quien era mercader de sedas y calcetero, o el de su padre, quien tenía el cargo de notario eclesiástico, además de señalar su inclusión en una clase media relacionada con trabajos en los que abundaban los conversos. De hecho, el propio oficio de su padre, Juan Rodríguez de Silva, como notario podría explicar la introducción de sus dos primeros hijos en el taller de Herrera el Viejo, dada la cercanía entre los escribanos y los iluminadores de libros, como es el caso de Juan de Herrera, padre del primer maestro de Velázquez. Estas referencias han permitido comprender cómo luego Velázquez traza su propia biografía, casi se inventa a sí mismo, ocultando datos para conseguir el tan ansiado hábito de la orden de Caballero de Santiago.

Por otra parte, también hemos descubierto una nueva hermana del pintor, llamada Francisca, así como información sobre su matrimonio y descendencia. Con el tiempo Francisca y su marido Carlos de Santa María, se ocuparán de los negocios de alquileres de casas que Velázquez y su suegra María del Páramo tenían en Sevilla. De manera análoga, aportamos noticias sobre su hermano Juan, quien también era pintor, reseñando su matrimonio, sus hijos y su muerte. También hemos incluido documentos inéditos sobre Francisco Pacheco, relacionado con la familia a raíz de la boda de su hija Juana con Velázquez, ya que cuando éste marcha a Madrid, deja al frente de su hacienda y propiedades al padre de Velázquez, quien es el encargado de administrar los alquileres de las casas, una de ellas donde vivió el propio pintor, arrendada a Alonso Cano.

En este sentido, el material recogido proporciona una visión más rica y compleja de las relaciones de Velázquez, revelando a pesar de su marcha a la Corte una preocupación por su familia en Sevilla, con la que tuvo contactos periódicos. También hay que destacar la cercanía del padre de Velázquez a la familia de su hijo, ya que incluso es el encargado de enterrar al mismo Pache$c o$, datos que nos proporcionan una visión más cercana de la intimidad del artista.

Además se aportan dos documentos inéditos hasta el momento como son los testamentos de los padres de Velázquez, hasta el momento desconocidos, puesto que incluso se ignoraban hasta la fecha de sus muertes. Su madre Gerónima Velázquez murió el 29 de marzo de 1640 , realizándose su testamento tres días antes, aunque debido a la gravedad de su enferme-

1 Méndez, L.: «La Familia de Velázquez: una falsa hidalguía», en Catálogo de la Exposición Velázquez. y Sevilla. Sevilla, 1999, pp. 33-49. 
dad dejó a su marido el poder para encargarse de lo concerniente a sus bienes. Gerónima dejó como únicos herederos a Diego Velázquez, pintor de cámara, y a Francisca Velázquez, la hermana que hemos descubierto. El padre de Velázquez, Juan Rodríguez de Silva, otorgó su testamento el 23 de mayo de 1643, dejando como herederos a sus únicos hijos vivos Diego Velázquez, citado como ayuda de Cámara del Rey, y Francisca, además de su nieto Cristóbal, hijo de Juan Velázquez, el pintor, y de María de Rueda, que tenía la edad de 18 años. Las noticias que nos proporcionan estos testamentos son muy importantes, ya que el nivel económico de la familia no era demasiado alto, a juzgar por las escasas pertenencias y dinero que dejan registrados, junto con las propiedades limitadas al domicilio familiar. Incluso aparecen viviendo en la casa de Juan Rodríguez de Silva algunos de sus hijos, como es el caso de la familia de su hijo Juan, que habitan la casa que su padre tenía en la collación de San Lorenzo durante casi diez años. Otro hecho a tener en cuenta es cómo el padre de Velázquez se encarga del domicilio que Francisco Pacheco y María del Páramo tenían en la calle del Puerco, actividad que pasa con su muerte al cuñado de Velázquez, Carlos de Santa María ${ }^{2}$.

La riqueza de estos hallazgos permite cerrar un capítulo de la historia de la familia de Velázquez, que transcurre cuando el pintor ha abandonado la ciudad, pero que es muy importante para conocer la figura de su padre y los aspectos sociales y económicos de su familia. Es ahora cuando deben hacerse nuevos análisis sobre Velázquez, aspectos todos ellos que a medida que se descubran nuevos documentos servirán para resolver los múltiples enigmas que todavía nos presenta el genial artista.

LUIS MÉNDEZ RODRÍGUEZ Universidad de Sevilla

\section{APÉNDICE DOCUMENTAL}

\section{MUERTE DE JUAN VELÁZQUEZ, HERMANO DE DIEGO. 7 septiembre de 1631.}

«En siete de septiembre de mil y seiscientos y treinta y un años los beneficiados desta iglesia enterraron en ella a $\mathrm{Ju}^{\circ}$ Velazquez casado con doña María de la Cueva vezino desta collación. No testó. En ese día se le dixo la misa cantada de requiem cuerpo presente dixola Fco Torreblanca».

Libro de Muertos, tomo 7. Archivo de la Iglesia de San Lorenzo. Sevilla, f. 267v.

\section{BAUTIZO DE JOSEFA, PRIMERA HIJA DE JUAN VELÁZQUEZ DE SILVA. 13 abril de 1625.}

«En domingo treze días del mes de abril de mil e seis e veinte y cinco años yo el lisenciado don Diego de Alburquerque beneficiado y cura de esta iglesia del Sr San Lorenzo baptisse a Josefa hija de Juan Velázquez y de doña María de la Cueva su mujer, fue su padrino Joan Sánchez de Texada vecino de San Ysidro al qual se le amonestó el parentesco espiritual que contraxo y lo firme ffecho utsupra

Ldo don $\mathrm{Di}^{\circ}$ de Alburquerque Salazar $\mathrm{Rd}^{\circ}$ y Cura»

Libro de Bautismos, tomo 7 (1621-29). Archivo de la Iglesia de San Lorenzo. Sevilla, f. 154v.

\section{BAUTIZO DE JUANA, SEGUNDA HIJA DE JUAN VELÁZQUEZ DE SILVA. 27 de junio de 1627.}

«En domingo veintisiete días del mes de junio deste año de mil y seiscientos y veintisiete años yo el ldo Baltasar de Ribero cura desta iglesia del Sr San Lorenzo baptise a Juana hija de Ju Velázquez y de doña María de la

2 En breve publicaré un estudio sobre estos testamentos, junto con nueva documentación encontrada sobre los padres de Velázquez, que enriquece la visión que se tiene sobre su etapa sevillana. 
Cueva su mujer vecinos desta collación fue su padrino Lucas Cerbera vecino de la collación de Santa María la Mayor al qual advertí la cognassión espiritual y lo firme fecho ut supra

el ldo Baltasar de Ribero»

Libro de Bautismos, tomo 7(1621-29). Archivo de la Iglesia de San Lorenzo. Sevilla, f. 217.

\section{CRISTÓBAL, HIJO DE JUAN VELÁZQUEZ DE SILVA. 26 de julio de 1629.}

«En jueves veinte y seis de julio de mill y seiscientos y veinte y nueve años baptize yo el maestro Alonso Osorio de Torres cura desta yglesia de S Lorenzo de Seva a Xpval hijo de Joan Velazquez de Silva y doña María de la Cueva su mujer, fue su padrino Carlos Roca, $v^{0}$ de la yglesia mayor y encargosele el parentesco espiritual y lo fe ut supra. El $\mathrm{M}^{\circ}$ Osorio de Torres cura».

Libro 9 de Bautismos. Archivo de la iglesia de San Lorenzo, f. 286v.

\section{BAUTIZO DE FRANCISCA, OCTAVA HERMANA DE DIEGO VELÁZQUEZ. 7 de noviembre de 1621}

«En domingo siete días del mes de noviembre de mil y seiscientos y veinte y un años bapticio el lisenciado Diego Albin de Moscoso beneficiado desta ygl ${ }^{\mathrm{a}} \mathrm{del}^{\mathrm{r}}$ san lorenco a Fran ${ }^{\text {ca }}$ hija de Juan Rodríguez de Silva y de doña Geronima Velasquez su mujer fue su padrino don Luys de Caransa veinte y cuatro de Sevilla y por verdad lo firmé ff. ut supra. Die Albin de Moscoso»

Libro de Bautismos, tomo 7(1621-29). Archivo de la Iglesia de San Lorenzo. Sevilla, f. 22.

\section{BAUTIZO DE MARÍA, ESCLAVA DE JUAN RODRÍGUEZ DE SILVA. 7 de noviembre de 1621.}

«En domingo siete día del mes de noviembre de mil y seiscientos y veinte y un años baptiçé el lisenciado Diego Albin de Moscoso beneficiado y cura desta iglesia del señor san Lorenzo a María esclava de Juan Rodríguez de Silva fue su padrino Melchor de Sanabria vecino de san vicente al qual se le amonestó el parentesco espiritual por berdad lo firmé ff. ut supra. Diego Albin de Moscoso»

Libro de Bautismos, tomo 7(1621-29). Archivo de la Iglesia de San Lorenzo. Sevilla, f. 22v.

\section{VELACIÓN Y DESPOSORIOS DE CARLOS DE SANTA MARÍA CON FRANCISCA VELÁZQUEZ. 9 y 13} de marzo de 1644.

«En domingo trece días del mes de março de mil y seiscientos y quarenta y quatro años yo el ldo Hernando Serrano de Horosco cura desta iglesia del Señor San Lorenzo de Sevilla despose por palabras de presente que hicieron verdadero matrimonio como lo manda el santo concilio de Trento y aviendo precedido dos amonestaciones porque en la tercera dispenso el $\mathrm{S}^{\mathrm{r}}$ Juez de la iglesia por causas que le movieron a Carlos de Santa María natural desta ciudad hijo de Juan de Santa María y de doña Antonia de León juntamente con Francisca de Silva Velázquez natural desta ciudad hija de Juan Rodríguez de Silva y de doña Gerónima Velázquez y aviendo tenido fe de no aver impedimento del licenciado don Diego Martel cura de la parroquia de Santa María Magdalena la qual

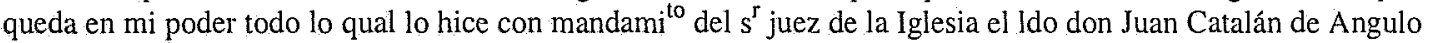
y refrendado de su not ${ }^{\circ}$ Xpoval López que queda en mi poder su $\mathrm{ff}^{\mathrm{a}}$ de quatro de março del dicho año siendo testigos el ldo Sebastián Sánchez cura de la iglesia de S. Lorenzo desta ciudad y el ldo Alonso Fernández Izquierdo presbit $^{\circ}$ capp $^{\text {an }}$ desta iglesia y vecino della y $\mathrm{Ju}^{\circ}$ Rodríguez de Silva vecino desta parroquia y porque con fe de verdad lo firmé en el dicho día mes y año. Ldo Herdo Serrano de Horosqui cura».

Al margen izquierdo: «desposorio Carlos de Santa María con doña Fca de Silva Velazquez velaronse los contenidos en este capítulo de nueve de octubre de 1644 en la ermita del señor San Onofre extramuros con licencia del sr juez de la iglesia el dotor don Xtobal Mantilla que queda en mi poder dijo la missa el lisenciado Bartolomé Belaganba presbitero con licencia de mi el ldo Hernando Serrano de Horosqueta cura desta dicha iglesia y porque conste lo firmé en el dicho día mes y año. Ldo Herd ${ }^{\circ}$ Serrano Horosqueta cura».

Archivo de la iglesia de San Lorenzo, libro 5 de Desposorios, f. $52 \mathrm{v}$.

\section{JOAN, HIJO DE FRANCISCA VELÁZQUEZ DE SILVA. 22 de enero de 1645.}

«En domingo ventidos días del mes de enero de mill y seis cientos y quarenta y cinco años yo el ${ }^{\text {do }}$ Hernando Serrano de Horosqueta cura desta yglesia del Sr San Lorenzo de Sevilla baptize a Joan hijo de Carlos de Santa María y de $d^{a}$ Fran $^{\text {ca }}$ de Silva Velázquez su mujer fue su padrino Fran ${ }^{\text {co }}$ de Escobar familiar del Santo Oficio de 
la Inquisición $\mathrm{v}^{\mathbf{0}}$ de la collación de San Ysidro encargósele el parentesco espiritual que a contraido y lo firme. $\mathrm{Ff}^{\mathrm{do}}$ ut supra. Ld $^{\circ}$ Herd $^{\circ}$ Serrano de Horosquetta cura».

Archivo de la iglesia de San Lorenzo, libro 9 de Bautismos, f. $92 \mathrm{v}$.

\section{JULIÁN ANTONIO, HIJO DE FRANCISCA VELÁZQUEZ DE SILVA. 9 de marzo de 1646.}

«En viernes nueve días del mes de março de mil y seis y quarenta y seis años yo el $l^{\text {do }}$ Hernando Serrano de Horozqueta cura desta yglesia del Sr San Lorenzo de Sevilla baptice digo esorcise y catequise porque en su casa le abia echado agua la comadre da Ana la Pulida por te nunese si dad Julián Antonio hijo de Carlos de Santa María y Camargo y de $d^{a}$ Fca Velázquez su mujer fue su padrino el contador Joan de Espinosa $\mathrm{vz}^{\circ}$ de la collación de san Bartolomé encargósele el parentesco espiritual que a contraydo y lo firme ut supra. Ldo Herdo Serrano».

Archivo de la iglesia de San Lorenzo, libro 9 de Bautismos, f. 145.

\section{PODER OTORGADO POR FRANCISCO PACHECO A JUAN RODRÍGUEZ DE SILVA. 11 de junio de 1624.}

«Sepan cuantos esta carta vieren como yo Francisco Pacheco pintor de imaginería vecino de esta ciudad en la collación de san Miguel otorgo e conosco que doy todo mi poder cumplido y legitimo como del dicho se requiere a Juan Rodríguez de Silva vecino de esta ciudad en la collación de sant Lorenzo para que por mi y en mi nombre e como yo me expidan e sirvan y vuelvan todas e quales que perpetuos sean (...) de sus bienes todas e quales que suman (...)n e otras cosas que se me deban e pertenescan que estan y debieren e pertenecieren de aquí a delante asi en esta ciudad de sevilla e como en otras quales partes y lugares fuera dello pastados los quales y en su escriptura de obligación el poder y secciones para que presente en mi nombre (...) en cumplimiento y arriende corrida o corriese de quales mis casas tta y otros bienes que tengo en esta dicha ciudad y en otras partes e para que bajas casas e las pueda arrendar e arriendes a las personas e para el tiempo que pareciese (...) e que pueda administrar e reparar las dichas casas (...). 11 de junio de 1624».

Archivo Histórico Provincial de Sevilla, Sección Protocolos Notariales, legajo 2523, ff. 263-263v.

\section{ARRENDAMIENTO DE JUAN RODRÍGUEZ DE SILVA DE UNAS CASAS EN LA ALAMEDA A ALON-} SO CANO. 28 mayo 1626

«Sepan quantos esta carta vieren como yo $\mathrm{J}^{\circ}$ Rodriguez de Silva vecino de esta ciudad de Sevilla en nombre y en voz de $F^{c o}$ Pacheco pintor $v^{\circ}$ en esta ciudad de $S e v^{a}$ por el poder que me otorgo ante el presente escribano público en el año de mil seiscientos veinte y cuatro otorgo e conosco que arriendo a Alonso Cano pintor de imagineria $v^{0}$ de esta dicha ciudad unas casas de morada que el dicho (...) tiene en esta ciudad en la calle de la alame$\mathrm{da}(. .$.$) en esta ciudad y se la arriendo por tiempo y espacio de dos años cumplidos primeros siguientes que a de$ ser y contar desde principio de julio que dixe este año de mil seiscientos veinte y seis en adelante por precio cada mes de siete ducados que a de ser obligación de me pagar a mi o a quien poder y causa del dicho $\mathrm{Fra}^{\mathrm{co}} \mathrm{Pacheco}^{\text {» }}$ (...). 28 mayo 1626

Archivo Histórico Provincial de Sevilla, Sección Protocolos Notariales, legajo 2535, ff. 320-320v.

\section{MUERTE DE GERÓNIMA VELÁZQUEZ, MADRE DE DIEGO VELÁZQUEZ. 29 de marzo de 1640.}

«En veintinueve días de março de mil y seiscientos y cuarenta años los beneficiados desta ygla enterraron en ella a d ${ }^{a}$ Gerónima Velázquez mujer de $\mathrm{J}^{\circ}$ Rodríguez secret ${ }^{\circ}$ del $\mathrm{Sr}$ Juez de la ygla dexo poder a dicho su marido para testar ante Rodrigo de Abrego escr ${ }^{\circ}$ de Sevilla en veintisiete de março deste año.

En treinta del dicho mes se le dixo una misa cantada de requiem cuerpo presente dixola $\mathrm{Ju}^{\circ}$ de Segura.»

En el borde izquierdo: «d Ger ${ }^{a}$ Velázquez

\section{Testo}

f. 72-10, f. 54-10, f. 55-10."

Libro de Muertos, tomo 9 (1640-47). Archivo de la Iglesia de San.Lorenzo. Sevilla, f. 14.

«En dos de diciembre mando decir Ju ${ }^{\circ}$ Rodríguez Sec. ${ }^{\circ}$ diez misas por el ánima de d. Ger ${ }^{2}$ Velázquez» Libro de Muertos, tomo 9 (1640-47). Archivo de la Iglesia de San Lorenzo. Sevilla, f. 72.

«En quince de julio $\mathrm{m}^{\text {do }}$ decir $\mathrm{J}^{\mathrm{o}}$ Rodríguez de Silva diez misas para Germ ${ }^{\mathrm{a}}$ Velázquez su mujer difunta como su alvacea». Libro de Muertos, tomo 9(1640-47). Archivo de la Iglesia de San Lorenzo. Sevilla, f. 54v.

«El test ${ }^{\circ}$ de da $\mathrm{Ger}^{\mathrm{a}}$ Velázquez

en 25 de julio $\mathrm{m}^{\text {do }}$ decir Ju Rodríguez de Silva diez misas para $\mathrm{Ger}^{\mathrm{a}}$ de Velázquez difunta su mujer como su alvacea». Libro de Muertos, tomo 9 (1640-47). Archivo de la Iglesia de San Lorenzo. Sevilla, f. 55. 


\section{TESTAMENTO DE GERÓNIMA VELÁZQUEZ. 27 de marzo de 1640}

«En el no de Dios sepan quantos esta carta vieren como yo Doña Gerónima Velázquez mujer legítima de Juan Rodríguez vecina desta ciudad de $\mathrm{Sev}^{\mathrm{a}}$ en la coll de $\mathrm{s}$ lor $^{\mathrm{o}}$ estando enferma y en mi juicio y en sentimiento natural el que dios nuestro señor fue servido de me dar creyendo (...) digo que por la gravedad de mi enfermedad de presente no puedo ordenar mi testamento y por el descargo de mi conciencia lo tengo común lado con el dicho Juan Rodríguez mi marido por tanto por la presente otorgo e conosco doy todo mi poder cumplido como de derecho se requiere al dicho Juan Rodríguez de Silva mi marido para que en mi nombre y como yo mesma pueda hacer ordenar mi testamento (...siguen disposiciones)

(...) y dexar todas las misas que con el tengo en común acuerdo que digan por mi alma y mandarme enterrar en la iglesia de San Lorenzo desta de San en la parte y lugares que le pareciere.

Yten otorgo que dejo por mis herederos universales a Diego de Silva Velázquez pintor de su Majestad residente en la vi ${ }^{\mathrm{a}}$ de Madrid y a doña Francisca de Silva Velázquez doncella mis hijos legitimos y del dicho Juan Rodríguez mi marido y dexar al dicho Juan Rodríguez por mi albacea y testamentario para cumplir y porque todo lo que él hiciera por mi testamento lo otorgue para en mi nombre (resto de condiciones), de lo a otorgue el prese escribano público y testigos en las casas de la morada de la otorgante en sevilla a veinte y siete días del mes de marco de mil seiscientos y cuarenta años y la otorgante dixo no saber firmar a cuyo ruego lo firmo el escribano publico (...) Antonio Lorenzo procurador de la real audiencia ve ${ }^{\circ}$ de esta ciudad y a Ana del Castillo doncella ve ${ }^{\circ}$ desta ciudad en la colla ${ }^{\mathrm{n}}$ de sta $\mathrm{M}^{\mathrm{a}}($...) don Francisco de Castro y Juan Garzon escribanos de sev».

Archivo Histórico Provincial, Sección Protocolos Notariales, legajo 6986, ff. 632v.-633.

\section{TESTAMENTO DE JUAN RODRÍGUEZ DE SILVA. 23 de mayo de 1647}

Al margen izquierdo: “ $« t e s t m^{\circ}$ de $\mathrm{ju}^{\mathrm{o}} \mathrm{Rs}^{\circ}$ de silba entregue el $\mathrm{tt}^{\mathrm{o}}$ a la $\mathrm{d}^{\mathrm{e}}$ en pliego de sello $\mathrm{pr}^{\mathrm{o}}$ en $\mathrm{v}^{\mathrm{te}} \mathrm{y}$ cinco de junio de $47 »$.

«En el nombre de Dios sepan cuantos esta carta de $\mathrm{T}$ vieren como yo Juan Rodriguez de Silva notario $\mathrm{m}^{\text {or }}$ del juz ${ }^{\circ}$ del $\mathrm{s}^{\text {or }}$ juez de la ig ${ }^{\mathrm{a}}$ desta ciu ${ }^{\mathrm{d}}$ de $\mathrm{Se}^{\mathrm{a}}$ en la collación de $\mathrm{s}^{\mathrm{a}}$ lorenco estando enfermo y en mi cuerdo juicio... hago y otorgo mi testamento (...) en la forma siguiente:

Primeramen ${ }^{\text {te }}$ encomiendo mi anima a Dios nuestro señor, a quien suplico perdone mis culpas y pecados (...).

Yten, quiero que mi cuerpo sea sepultado en la dicha iglesia de san lorenço en la sepoltura y entierro que alli me fuere dada y $\operatorname{og}^{\mathrm{do}}$ a la orden y forma de mi entiero lo remito al parecer de mis albaceas.

Yten $\mathrm{m}^{\mathrm{do}}$ que el día de mi entierro si fuere ora y si no que se diga por mi anima una misa cantada de req $^{\text {en }} \mathrm{y}$ se pague la limosna.

Yten $\mathrm{m}^{\mathrm{d}}$ se digan por mi anima doscientas missas reçadas las cinq ${ }^{\text {da. }}$ En la dicha iglesia de san lorenço por for $^{\text {ma }}$ y las demás en las iglesias y mones ${ }^{\text {rios }}$ que pareciesen a mis albaceas.

Yten $\mathrm{m}^{\mathrm{do}}$ a las cofradías del $\mathrm{ss}^{\mathrm{mo}}$ sacram $^{\text {to }}$ y venditas almas de purg ${ }^{\circ}$ de la dicha $\mathrm{ig}^{\mathrm{a}}$ de san lorenço a cada parte dos rls y a las mandas pias lo acostumbrado.

Yten declaro que devo al ospital del cardenal desta ciu $^{\mathrm{d}}$ trecientos y treinta y tres reales por la renta de un tercio que se cumplio a fin de abril deste año de $\mathrm{m}^{1}$ e $\operatorname{ses} \mathrm{q}^{\text {ta }}$ y siete de las casas en que vivo que tiene de por vida Diego Velasquez mi hijo ayuda de cámara de su mag ${ }^{\mathrm{d}}$.

Yten declaro que devo al ospital del amor de dios desta ciu ${ }^{\mathrm{d}}$ ciento y sesenta y seis reales del tercio $\mathrm{pi}^{\circ} \mathrm{del}$ mes de abril desde dho año de la renta de las casas que tiene de por vida de dho ospital doña $\mathrm{M}^{\mathrm{a}}$ Paramo que son en esta ciu ${ }^{\mathrm{d}}$ en la collacion de s miguel en la calle del puerco las que yo e administrado en virtud del poder de la dha d" Maria Paramo.

Yten $\mathrm{m}^{\text {do }}$ se ajuste la $\mathrm{q}^{\text {ta }}$ con la dha doña Maria Paramo de lo que yo e que cobrado de las dhas casas y de lo della (...).

Yten declaro que yo tube en mi casa a $\mathrm{Ju}^{\circ}$ Velazquez mi hijo y a $\mathrm{d}^{\mathrm{a}}$ Maria de la Cueva su mujer y a sus hijos en mi casa por mas $t^{0}$ de diez años y los sustente y alimente y les di casa en que vivieron todos el dicho tiempo sin gastar en cosa alga de sus bienes en que gaste en cada un año los dhos alimentos y casa les di y en bestir a sus hijos mas de ciento y cinq ${ }^{\text {ta }}$ ducados cada un año declaro asi por descargo de mi conciencia y porque se baje y desg $^{\text {ve }}$ la cantidad a Xpbal de la Cueva mi nieto hijo de los susodichos y los traigo a collación y particion con los demas de mis hijos y erederos (...)

Yten declaro que al $\mathrm{t}^{\mathrm{io}}$ que se cassó $\mathrm{d}^{\mathrm{a}}$ Fran ${ }^{\mathrm{ca}}$ Velazquez mi hija ligitima con Carlos de Santamaría su marido que abra tres años poco mas o menos le di $\mathrm{p}^{\mathrm{a}}$ su casam $^{\text {to }}$ lo que pareciere por la carta de dote que paso ante Mateo de Almonacid escrin ${ }^{\circ} \mathrm{P}^{\mathrm{co}}$ de $\mathrm{ss}^{\mathrm{a}}$ todos los quales dhos vienes que le di por la dha carta de dote son los que 
están en las casas de mi morada respecto de que los susodichos an vivido y estan en mi cargo y asi mismo los e sustentado y alimentado $t^{0}$ de tres años (...) declarolo así para conste dello.

Yten conformandome con las leyes destos reinos desde luego mejor e por mejorada a la dha $\mathrm{d}^{\mathrm{a}} \mathrm{Fran}^{\mathrm{ca}}$ Velazquez mi hija mujer lixitima del dho Carlos de Santamaría en este y remanente doy quinto de mis vienes muebles e raices deudas y acciones por el amor que la tengo y por aberme sido obediente y acudidome a todas mis necesidades y enfermedades y por que a desde mi $\mathrm{v}^{\mathrm{d}}$ (demás disposiciones)

Yten declaro que para executar y cumplir con mi testamento nombro por mis albaceas a Carlos de Santa María y a don Diego Carrillo clerigo presb ${ }^{\circ}$ desta ciudad

Yten mando a doña ynes luisa mi sobrina de edad de diez años quatro sillas negras de vaqueta y una media cama de madera colorada y dorada y cien reales de plata los cuales se entreguen a da María de Saravuia su madre.

Yten mando que todos mis bienes muebles sean sacados a subasta pública. Nombro por herederos universales a Diego Velazquez ayuda de camara de su majestad y a $\mathrm{d}^{\mathrm{a}}$ Fran $^{\mathrm{ca}}$ Velazquez hijos legitimos y a Cristobal de la Cueva mi nieto hijo legitimo de Juan Velazquez difunto y Maria de la Cueva (...)».

Archivo Histórico Provincial. Sección Protocolos Notariales, legajo 532, ff. 393-394v.

\section{LOS TASADORES DIEGO VELÁZQUEZ Y JUANA PACHECO}

El año 1999 conmemora el IV centenario del nacimiento de Diego de Silva y V̧êlázquez, uno de nuestros más geniales e insignes pintores de todos los tiempos de la historia universal. La búsqueda documental de nuevas fuentes que puedan enriquecer la historia de la pintura española, unida a una pequeña dosis de casualidad, ha querido que realicemos una novedosa aportación sobre algún aspecto biográfico y laboral de un personaje al que, por la amplitud de la bibliografía sobre él ya existente, parece que poco restaba por añadir ${ }^{1}$.

Este nuevo hallazgo nos permite descubir dos vertientes poco comunes en la hasta ahora conocida trayectoria del artista: una, como tasador de pinturas ${ }^{2}$; otra, y por primera vez para nosotros, trabajando bajo un mismo encargo y de manera conjunta al lado de su mujer Juana Pacheco.

Lo que aquí vamos a tratar ocurrió en Madrid durante 1636. Es el período entre su primer y segundo viaje a Italia. Un tiempo en el que la llamada Torre de la Parada, camino de El Pardo madrileño, se encuentra a punto de engalanarse con los lienzos pintados por Velázquez para tal regio encargo. Probablemente el pintor debía estar finalizando con destino a este mismo lugar el retrato venatorio del príncipe Baltasar Carlos, pintado al parecer entre los meses de octubre de 1635-1636 ${ }^{3}$. Recordemos que ese año Velázquez, pintor del rey hacía ya más de una década, fue nombrado Ayuda de Guardarropa de Su Majestad ${ }^{4}$. Tres me-

1 El documento base de este artículo, fue citado por Peter Cherry: New documents for Velazquez in the 1620s. En «The Burlington Magazine», vol. CXXXIII, n. ${ }^{\circ} 1.055$, febrero 1991, pp. 108-115, nota n. ${ }^{\circ} 44$.

2 Veáse J. López Navío: Velázquez tasa los cuadros de su protector D. Juan de Fonseca. En «Archivo Español de Arte», 1961, tomo XXXIV, pp. 53-84.

3 Véase cat. exp. Velázquez. Museo del Prado, del 23 de enero al 31 de marzo; n. ${ }^{\circ} 45$, pp. 276-281. Madrid, 1990.

${ }^{4}$ Con fecha 28 de julio de 1636. Véase Rodríguez Villa, Antonio: La Corte y Monarquía de España en sus años de 1636 y 1637 con curiosos documentos sobre corridas de toros de los siglos XVII y XVIII. Madrid, 1886, pp. $27-28$. 